\title{
A IMPORTÂNCIA DO LETRAMENTO DIGITAL NAS AULAS DE LÍNGUA INGLESA
}

\author{
The Importance of Digital Literacy in English Classes
}

Tayane Kizze dos Santos Pereira ${ }^{1}$ - UFS

RESUMO: Devido à criação e introdução das novas tecnologias no ambiente escolar, abre-se uma nova perspectiva para o ensino-aprendizagem de língua inglesa. Atualmente muitas coisas na vida das pessoas têm mudado com o avanço tecnológico, no entanto, nem todos conseguem acompanhar essas mudanças ou fazer uso das tecnologias para o próprio aprendizado. Por isso se torna essencial que as escolas formem cidadãos que saibam transitar entre os meios eletrônicos, sem contudo aceitar passivamente tudo que eles transmitem; daí se torna essencial a prática do letramento digital nos dias de hoje. É sobre a importância de tal letramento, das relações dos professores com as tecnologias e o uso que é feito delas em sala de aula que se baseia o presente trabalho.

PALAVRAS-CHAVE: Novas tecnologias; Letramento digital; Ensino; Língua inglesa

\begin{abstract}
Due to the creation and introduction of new technologies in the school environment, a new perspective to teaching and learning of English is opened. Nowadays, many things in people's lives have changed with technological progress, however, not everyone can go along with these changes or make use of technologies for their own learning. Therefore it is essential that schools form citizens who can move through the electronic media, without accepting passively everything they broadcast. Then it becomes essential digital literacy practice nowadays. This paper is based on the importance of this literacy, teachers' relations with technologies and how they are used in classrooms.
\end{abstract}

KEY-WORDS: New Technologies; Digital literacy; Teaching; English language

\section{INTRODUÇÃO}

Com o advento e propagação das novas tecnologias ao redor do mundo, muitos aspectos do cotidiano têm mudado pelo menos na vida de muitas pessoas: a distância entre elas tem diminuído, as informações cruzam o globo rapidamente, muitos processos agora são feitos online, como por exemplo, o pagamento de contas, compras, cadastros etc. É também sabido por muitos que, ao permitir que qualquer pessoa possa publicar, falar, questionar algo através de uma ferramenta como a Internet, o individuo passa a ter uma parcela maior de participação na sociedade, como bem indicam as Orientações Curriculares para o Ensino Médio (BRASIL, 2006, p. 95). Diante de tantas mudanças,

\footnotetext{
${ }^{1}$ Este trabalho está vinculado ao projeto de pesquisa Formação continuada de professores de língua inglesa em Sergipe a partir das teorias dos Novos Letramentos, financiado pelo CNPq (processo n ${ }^{\circ}$. 401394/2010-7) e coordenado pelo Prof. Dr. Vanderlei José Zacchi, do Departamento de Letras Estrangeiras da Universidade Federal de Sergipe
} 
a educação não pode ficar estagnada; ela também precisa acompanhar a evolução tecnológica. Dessa forma, no Brasil, “o Ministério

da Educação projetou o Proinfo, cujo principal objetivo é a introdução das Novas Tecnologias de Informação e Comunicação na escola pública, como ferramenta de apoio ao processo de ensinoaprendizagem" (BRASIL, 2006, p. 95).

Com todo o processo globalizante e meios eletrônicos que permitem que se faça a ponte entre o indivíduo e o mundo, aproximando os povos, muitos dos valores sociais têm sido transformados e reinventados. A educação precisa acompanhar tais mudanças; os alunos, como seres pertencentes à sociedade, precisam saber lidar com o desconhecido a todo o momento; os professores precisam estar preparados e preparar seus alunos para o novo e também para que estes sejam capazes de, através de suas consciências críticas, questionar suas posições na sociedade. Sendo assim, abordagens de ensino que por ventura tenham ênfase em conhecimentos estáticos não mais fazem sentido. Segundo as OCEM,

\footnotetext{
As propostas epistemológicas (de produção de conhecimento) que se delineiam de maneira mais compatível com as necessidades da sociedade atual apontam para um trabalho educacional em que as disciplinas do currículo escolar se tornam meios. Com essas disciplinas, busca-se a formação de indivíduos, o que inclui o desenvolvimento de consciência social, criatividade, mente aberta para conhecimentos novos, enfim, uma reforma na maneira de pensar e ver o mundo. (BRASIL, 2006, p. 90).
}

De acordo com as Orientações Curriculares para o Ensino Médio (2006, p. 113), as teorias dos novos letramentos "poderão contribuir para ampliar a visão de mundo dos alunos, para trabalhar o senso de cidadania, para desenvolver a capacidade crítica [...]". Conforme essas teorias, os textos não são mais vistos apenas como aqueles escritos; imagens, sons, gestos também são. Então novas formas de letramento são necessárias para que se possa atender a essas novas formas de texto, fala-se assim em multiletramentos, dentre eles o letramento digital.

O ambiente virtual, como já dito, é uma realidade para grande parte das pessoas hoje em dia. Nesse ambiente encontram-se animações, fotografias, hipertexto, imagens, sons etc. O aprendiz, por sua vez, tem que saber como navegar entre tantas opções e tantas formas diferentes de texto, selecionando o que for relevante para sua pesquisa, e analisando com um senso crítico as informações que cheguem a ele, pois é importante que não se aceite com passividade tudo a que se está exposto. Dentro de todo esse contexto, o letramento digital se torna essencial atualmente.

O presente artigo se baseia nesse panorama dito até aqui, nas teorias dos novos letramentos, em especial o letramento digital, assim como no projeto de pesquisa "Formação continuada de 
professores de língua inglesa em Sergipe a partir das teorias dos novos letramentos", apresentando alguns resultados aliados a uma discussão teórica.

\title{
METODOLOGIA
}

Para a realização desse projeto que se encontra em andamento, está sendo feita uma pesquisa qualitativa. De acordo com Teis D.T. e Teis M.A. (2006),

\begin{abstract}
Uma pesquisa com essa abordagem caracteriza-se pelo enfoque interpretativo. [...] Entre os tipos de pesquisa qualitativa está a do tipo etnográfico. Para que uma pesquisa seja reconhecida como do tipo etnográfico, deve preencher, antes de tudo, os requisitos da etnografia que tem como premissas a observação das ações humanas e sua interpretação, a partir do ponto de vista das pessoas que praticam as ações. (2006, p. 1)
\end{abstract}

Em um primeiro momento da realização da pesquisa foi feito um levantamento da literatura sobre os temas tratados, tais como multiletramentos, multimodalidade, globalização, transculturalidade etc. Foram realizadas reuniões com os participantes envolvidos para debater os textos lidos, além disso, foi criado um blog e um espaço no Google groups para que as discussões pudessem se estender além do espaço físico.

Num segundo momento, foi elaborado um questionário aplicado a alguns professores de inglês da rede pública de Sergipe. O objetivo era conhecê-los melhor, bem como a metodologia de ensino utilizada por eles em suas aulas e seus conhecimentos prévios sobre os Novos Letramentos. Após a aplicação do questionário, os docentes que se interessaram em participar da pesquisa e disseram ter disponibilidade para os encontros foram selecionados e, posteriormente, reuniões foram feitas com os mesmos a fim de discutir os temas abordados, as perspectivas desses professores acerca do ensino da língua, assim como também foram espaços para que eles pudessem expor suas frustrações e experiências.

Após alguns encontros e muita discussão foram divididos três subgrupos para a realização de uma entrevista, a qual era dividida em quatro partes. A primeira continha questões gerais, como por exemplo, se os professores achavam que os novos letramentos podem dar conta de tudo o que se propõe a fazer, se já tinham notado alguma mudança na reação dos alunos, qual o papel da língua inglesa nos dias de hoje e o que eles gostariam de mudar em suas aulas. A segunda parte era de perguntas específicas (sobre multiletramentos e multimodalidade, letramento digital e letramento crítico) que variavam de acordo com cada subgrupo, a terceira era destinada a cada professor em particular e a quarta parte era a análise de três imagens: os professores viam apenas as fotografias e 
precisavam descrevê-las e fazer uma conexão entre elas. Posteriormente era mostrado o título que acompanhava tais imagens "Mexico police find 513 US-bound migrants in trucks" e eles falavam sobre as impressões que tinham e sobre o tema de imigração tratado ali, que depois foi associado à questão dos migrantes que saem de uma região para a outra dentro do próprio Brasil, fazendo dessa maneira a conexão entre o global e o local.

A ideia, a partir desse ponto da pesquisa, é que cada subgrupo trabalhe separadamente temas específicos realizando a produção de atividades que podem ser trabalhadas com os alunos em sala de aula, unindo ainda mais a teoria à prática. Além das reuniões dos subgrupos, há uma vez por mês um encontro com todos os participantes para que se possa ter, além das discussões teóricas, o compartilhamento e debate dos resultados obtidos.

O presente trabalho busca analisar os dados alcançados através das respostas das entrevistas, questionários e dos relatos e informações redigidos nos diários de campo, os quais são feitos por todos os envolvidos na pesquisa. É de relevância mencionar que citações reproduzidas neste artigo referentes a esses envolvidos são feitas com nomes fictícios, preservando assim a identidade de cada um. Os dados serão analisados à luz da importância do letramento que se dá por meios eletrônicos, a relação que os professores têm com as tecnologias e, por fim, quais usos eles fazem das mesmas em sala de aula.

\section{LETRAMENTO MIDIÁTICO E DIGITAL}

Alguns dos autores que escreveram sobre a importância do uso de mídias na educação foram Carr e Porfilio (2009). No artigo Computers, the media and multicultural education: seeking engagement and political literacy, baseado em duas de suas pesquisas, os autores falam sobre um letramento político que trate de questões sociais, através de letramento midiático e digital. Segundo The Association for Media Literacy (www.aml.ca), o letramento midiático diz respeito ao processo de compreensão e utilização das mídias de massa. Esse letramento também está preocupado em ajudar os alunos a desenvolver uma compreensão consciente e crítica da natureza dos meios de comunicação de massa, das técnicas utilizadas por eles, e o impacto dessas técnicas.

O que se pode perceber nessas pesquisas de Carr e Porfilio, no entanto, é que o letramento midiático ainda não é muito bem compreendido e não recebe muito valor. Muitos professores não receberam esse tipo de formação, não estão acostumados a isso e, portanto, não fazem esse letramento em suas aulas. O mesmo acontece com o letramento digital. Segundo os dois autores, muitas instituições têm promovido aos seus alunos cursos sobre o manejo com o computador que 
envolve apenas as habilidades mecânicas como digitar um texto e fazer tabelas, por exemplo, mas elas falham ao não guiar os alunos ao reconhecimento de como os computadores também são responsáveis por perpetuar desigualdades sociais para muitos cidadãos, ou seja, não há uma formação crítica através do uso dessas ferramentas.

Outro instrumento tecnológico que pode contribuir no processo de aprendizagem é o vídeo game, assunto tratado por Ilana Snyder no capítulo 'Technology' do livro The Literacy Wars: why teaching children to read and write is a battleground in Australia (2008). Estudos têm mostrado a relação entre jogos de computador e aprendizado. Através dos jogos, as pessoas adquirem várias habilidades, pois eles envolvem aspectos visuais, sonoros, escritos e os jogadores interagem. Por meio dos jogos computadorizados os alunos podem ficar mais interessados e envolvidos, pois nesse espaço virtual eles são ativos, se esforçam para atingir determinados objetivos e também é possível criar e controlar situações enquanto jogam; isso pode dar aos alunos uma sensação que está associada à idéia de prazer. Como defendido por Gee (2007, p. 10), “Good video games give people pleasures. These pleasures are connected to control, agency, and meaningfulness. But good games are problemsolving spaces that create deep learning, learning that is better than what we often see today in our schools".

Os jogos não são mais aqueles de guerra, violentos, que na maioria eram utilizados por meninos. Hoje em dia há vários jogos educativos através dos quais os alunos podem aprender de forma muito mais lúdica e interessante do que através de livros impressos. Segundo os autores James Paul Gee e Henry Jenkins (apud Snyder, 2008, p. 165), quando crianças e jovens jogam videogames eles experimentam uma forma mais poderosa de aprender do que quando eles estão numa sala de aula.

A presença de jogos e conversas online, internet, uso de celulares, mensagens de texto, blogs, e-mail etc tem se tornado cada vez mais frequente dos anos 1990 para cá. Com isso surgiram novos tipos de textos e práticas sociais. O letramento agora envolve hipertextos, participações em blogs, discussões online etc. Os alunos trazem suas experiências de fora da escola para as salas de aula. No entanto, de acordo com Kenway (apud Luke, 2000, p. 72) "teaching students about new technologies in their social and cultural work and leisure contexts has not been a high priority in curriculum development".

\section{RELAÇÃO PROFESSOR/TECNOLOGIA}


Levando-se em consideração a relevância de um letramento midiático, digital, a importância que tem os videogames nas salas de aula, bem como o preparo de professores para trabalhar dessa forma com os alunos, é válido citar um fato ocorrido em uma das reuniões do projeto e que foi registrado em diário de campo pessoal.

Em um dos encontros foi pedido aos professores que levassem textos através dos quais pudessem ser trabalhadas algumas questões como "What values or attitudes are being presented and how do they relate to my own and others?", "Are there gaps and silence in the text - who is represented and who is not?", "What histories and experiences are included or omitted?" (adaptado de ANSTEY; BULL, 2006, p.38). A proposta da atividade era fazer com que os professores pensassem como utilizariam e explorariam os textos com seus alunos.

Durante a realização da atividade, foram divididos alguns grupos para que houvesse o debate. Uma das participantes levou um texto que falava sobre o jogo Second Life, por meio do qual é possível criar um avatar e agir como se estivesse vivendo a realidade. Porém a professora Hillary disse que não utilizaria esse texto numa sala de aula, pois não gostaria de ser cúmplice em propagar um vício, como o jogo de vídeo game, entre os alunos.

No entanto, essa docente não levou em consideração a importância de um texto que fala sobre uma coisa recorrente e atual na vida dos alunos que é o jogo digital (no caso em questão, o Second Life) e que pode suscitar várias questões, como por exemplo, a questão da identidade (já que os jogadores criam um personagem que representa a si próprio) ao saber se os alunos realmente se identificam com os avatares criados e se agem como eles. Outra questão que poderia ser discutida é a relação do virtual com o real: se a casa, o bairro, a cidade do jogo são de alguma forma parecida com a realidade deles, ou ainda, o que e por qual razão são diferentes, o que gostariam de mudar e como poderia ser feito isso, enfim, questões como as da atividade proposta acima mencionada, realizada com os professores, poderiam ser levantadas.

Exemplos como o do caso do Second Life mostram como os professores podem e precisam desenvolver uma consciência mais crítica nos alunos, para que eles possam participar mais ativamente da sociedade da qual fazem parte. Na situação em questão isso seria feito através de um ambiente digital, o que vem afirmar como professores e alunos precisam ser letrados digitalmente nessa nova era tecnológica. Como colocou Luke:

[...] educators need to become familiar with the many issues at stake in the 'information revolution' so that we know how and where we must intervene with positive and critical strategies for Multiliteracies teaching, and how to make the best and judicious use of the many multimedia resources available. (LUKE, 2000, p. 71) 
Segundo Snyder (2008, p. 168), desde os anos 1970 que os professores mostram uma certa rejeição aos computadores. Estes eram (e são) ainda muito usados para exercícios mecânicos e como uma ferramenta de escrita. Os professores mais jovens (especialmente) têm usado mais essa ferramenta em suas aulas, mas ainda assim são resistentes.

Sobre a relação professor/tecnologia é válido destacar um trecho de uma das entrevistas, no qual a entrevistadora pergunta a professora sobre o curso da Proinfo (Programa Nacional de Tecnologia Educacional) ofertado pelo governo:

Entrevistadora: e você sabe, você tem alguma ideia de quantos começaram e quantos terminaram?

Rejane: Não terminaram todos não. Como todo curso à distância, não terminaram todos porque a maioria vai e não tem habilidade com internet, com computador e fica pelo caminho. Eles dão o critério, mas como nem todo mundo aparece dentro daquele critério ai não tem critério, porque não tem habilidade com internet.

Ai fica menos da metade. Isso é pra longo prazo e se a universidade começar a formar pra tecnologia porque senão nem a longo prazo. Porque tem que dominar, não adianta você pegar o retroprojetor e projetar o conteúdo só. A questão é você aprender com a tecnologia.

A professora tá usando o laptop pra ensinar ditado. Ai eu digo "e mudou o que?"... "ah, não mas os alunos tão aprendendo a digitar". Eu digo "sim, mas ao invés de tá fazendo isso, ela poderia tá usando o gênero textual" ou então mandar mensagem um pro outro. Ele faria a atividade da escrita e aprendia a digitar, e não fazer cópia.

A passagem acima é um exemplo de como muitos docentes ainda não dominam o uso dos recursos tecnológicos e como a capacitação desses professores ainda pode melhorar. A entrevistada também fala da importância de se fazer o uso adequado das tecnologias, pois não adianta a mera transposição dos meios; uma vez que a proposta é educar os alunos, formar cidadãos também utilizando-se dos meios digitais, os quais fazem parte do cotidiano dos discentes cada vez mais.

Com o uso da internet algumas coisas têm mudado, como por exemplo o uso de bibliotecas virtuais, de sites de busca para fazer pesquisas, de ferramentas como o Youtube para apresentação de trabalhos escolares, utilização de redes sociais como Orkut, Facebook, MSN, nos quais há uma troca muito grande de informações. O uso de novas tecnologias e da mídia passa a definir o contexto de ensino-aprendizagem. Estas precisam passar por um processo crítico, pois nem tudo que vem delas pode ser tomado como verdade. Os indivíduos que são expostos às tecnologias devem relativizar as informações que chegam a eles e cabe às escolas esse papel de instruir os alunos nesse sentido. Isso mostra mais uma vez a importância do letramento digital. Sobre tal Gilster (apud Araújo, 2006, p.138) afirma:

Digital literacy is the ability to understand and use information in multiple formats from a wide range of sources when it is presented via computers. [...] Acquiring digital literacy for Internet use involves mastering a set of core competencies. The most essential of these is the ability to make informed 
judgments about what you find on-line, for unlike conventional media, much of the Net is unfiltered by editor and open to the contributions of all. [...] Other competencies branch inevitably from your ability to think critically. You will have to target your reading using the model of the electronic word hypertext and its cousin hypermedia, the linking of the individual noun or phrase to supporting text or other forms of media. Sequential reading is supported by nonlinear jumpes to alternative idea caches, with inevitable repercussions for comprehension. The journey through text becomes anriched with choices. (2006, p.138)

Como é possível perceber o mundo virtual se torna mais democrático do que outros tipos de mídia ao permitir que qualquer pessoa com acesso à internet possa, através desse meio, se expressar, trocar informações, se comunicar com outros etc. Por ser um espaço abrangente, ao navegar pela web as pessoas precisam não só de habilidades técnicas, como por exemplo, saber manusear ferramentas presentes em computadores, mas também ter noção de como os usos feitos através dessas máquinas estão ligados às práticas sociais, uma vez que são acessadas por pessoas, dentro de um determinado contexto, com determinados objetivos. Além disso, ao navegar pela internet é preciso ter senso crítico para avaliar a série de informações produzidas livremente por diversos indivíduos.

\section{USO DE NOVAS MÍDIAS EM SALA DE AULA}

Uma das perguntas específicas da entrevista concernente ao letramento digital foi "Como você utiliza ou utilizaria as tecnologias digitais no ensino de língua inglesa?”. A professora Vanessa disse utilizá-las para passar clip, músicas ou filmes (dublados), tendo como objetivo a interpretação, opinião dos alunos. Segundo a mesma, o diferencial da mídia, no que diz respeito à atividade proposta, é o visual, que chama mais atenção deles. Já a professora Ana Maria disse que ao trabalhar usando a internet pediu aos alunos que fizessem uma pesquisa sobre países nos quais se fala língua inglesa. $\mathrm{O}$ objetivo da atividade era apenas trabalhar com o hipertexto.

Sabe-se, no entanto, que o letramento digital vai além dessas atividades propostas. Ele confere ao leitor uma nova maneira de ler e processar as informações. Já que o mundo virtual é muito abrangente, o aprendiz precisa saber quais as fontes de onde ele está tirando tais informações e se a mesmas são confiáveis, como selecionar entre a gama de dados quais são relevantes para sua pesquisa e interpretá-los. Os professores precisam ter consciência do valor dessa formação tecnológica para seus alunos, uma vez que isso se torna importante tanto como forma de entrada no mercado de trabalho como forma de socialização.

Os professores falaram sobre a importância das tecnologias na educação ao responderem a pergunta “Como você vê o papel das novas mídias no ensino de língua inglesa?". Ana Maria disse que vê com grande relevância, mas que a escola não dispõe dessas mídias, por isso é difícil utilizar e, 
mesmo fora da escola, poucos têm acesso. O mesmo problema de estrutura escolar é citado por outra entrevistada, professora de duas escolas (municipal e estadual) que afirma que por mais que os alunos gostem e interajam, é difícil utilizar as tecnologias com frequência por falta de recursos, como é possível ver no trecho abaixo retirado da entrevista:

Entrevistadora: Em geral, quais são os tipos de atividades? E com que freqüência você utiliza?

\begin{abstract}
Vanessa: Eu utilizo mais o giz e o apagador. E agora o livro, mas uma vez por mês eu levo música, eu levo um clip, alguma coisa assim, uma vez por mês, porque não dá não, pra passar sempre, sabe? Mas eu sempre levo.

Entrevistadora: E, e, em geral, como é que eles reagem, como é que é o uso?

Vanessa: Ah, eles gostam. Quando eu levo música, quando eu às vezes levo eles lá pro laboratório, porque assim, às vezes eu levo os alunos do município e peço a diretora do Estado, ai peço. Aí às vezes eu levo esses alunos do município pra esse laboratório do Estado, mas é de vez em quando porque eles moram no povoado aí não tem transporte. Aí quando arranja um transporte eu levo eles pro laboratório, e aí uma vez que eu levei foi nessa vez do clip que eu passei e eles interagiram direitinho.
\end{abstract}

A má infraestrutura escolar é um problema inegável para a aplicação de uma abordagem levando em conta o letramento digital: faltam computadores, internet, ou ainda quando tem, o acesso é limitado, como relatado por uma das professoras. A falta de conhecimento tecnológico por partes de alguns também se torna um empecilho. Dessa forma, a formação do profissional se torna tão importante quanto a infra-estrutura do colégio.

A professora Ana Maria relatou ter feito o curso “Tecnologias na Educação: ensinando e aprendendo com as TICs", que foi ofertado aos professores da rede estadual em 2009 e que tratava das tecnologias na sala de aula. O reflexo do curso em sua prática foi pedir que os alunos fizessem uma pesquisa para que assim utilizassem o hipertexto, como mencionado mais acima. Vanessa também disse ter feito um curso de como abranger ferramentas tecnológicas em sala de aula e disse trabalhar com o Linux e as ferramentas educacionais que o sistema operacional disponibiliza, como por exemplo, o portal do professor, o domínio público para retirar questões e provas (utilizando mais para aulas de português) e jogos como forca (para aulas de inglês). No excerto abaixo ela fala do objetivo do uso dessas ferramentas:

Entrevistadora: E o que que você passa, dessas coisas que você tem aprendido no curso, você faz, você insere nas suas aulas com qual objetivo, qual seu propósito principal?

Vanessa: Os jogos, o objetivo é eles entrarem em contato com a língua porque, se você botar lá a forca aí tem "partes da casa", aí eles aprendem direitinho, muitas coisas eles conseguem. Quando eu faço o uso desses jogos, eu quero mais que eles entrem em contato com a língua, não tem senso crítico não, essas coisas. É só a parte de vocabulário mesmo. É isso. 
O exemplo acima citado representa bem o uso mecânico que é feito através das novas mídias. Alguns professores, nos questionários, disseram usar o computador para procurar provas de vestibular, exercícios, músicas etc, mostrando preocupação em trabalhar mais a parte gramatical, interpretação de texto, vocabulário. No entanto tais atividades poderiam ser feitas mesmo sem a utilização de um computador; o que acontece nos exemplos mencionados é a transposição de meios: da folha de papel para a tela. Dessa maneira percebe-se que, como citou Snyder (2008):

Some literacy teachers have found ways to exploit the opportunities for rich learning that the new media offer and to help students become critical and capable users. However, most have been slow to adjust and, when they do use the technologies, it's often to achieve print-based purposes in printoriented ways. (2008, p. 181)

\section{CONCLUSÕES}

Devido ao encurtamento das distâncias por conta do advento e propagação das tecnologias, grande parte da humanidade pode, hoje em dia, saber em questões de segundos fatos que ocorrem na outra parte do globo. Atualmente os indivíduos estão expostos a uma gama enorme de informações que são produzidas livremente por várias pessoas. Nesse mundo sem fronteiras, como pode ser chamado o ambiente virtual, é imprescindível que as pessoas estejam aptas a transitar, não apenas com conhecimento das ferramentas que existem em um computador, mas também com um senso crítico que lhes permita não absorver passivamente toda a informação que lhes chega, sabendo selecionar o que é relevante ou não para si. O mesmo é válido para a mídia; todos os dias os meios de comunicação 'bombardeiam' as pessoas com notícias, informações e fatos, então é igualmente importante que cada um saiba perceber que nem tudo que vem da mídia precisa ser necessariamente aceito.

Cabe às escolas a responsabilidade de instruir seus alunos nesse sentido, pois assim estarão educando cidadãos para a vida, prontos para agir em situações novas, inesperadas, num contexto mais amplo do que o ambiente escolar. Dessa maneira essas instituições não apenas estariam incluindo os indivíduos no mercado de trabalho, como também na sociedade. Essa formação cidadã pode também se dar por meio do ambiente eletrônico, tendo-se então, o letramento digital, tão importante numa era que se torna cada vez mais tecnológica.

Igualmente importante é que não só os alunos sejam letrados digitalmente; os professores também precisam ser, para que saibam trabalhar com os discentes de maneira apropriada e não só transponham práticas para o meio digital - o que alguns docentes ainda fazem, como ficou claro em alguns relatos no decorrer das entrevistas. 


\section{REFERÊNCIAS}

AML. What is digital literacy. Disponível em < http://www.aml.ca/whatis/>. Acesso em: 15 jul. 2011

ANSTEY, Michèle; BULL, Geoff. Teaching and Learning Multiliteracies: Changing Times, Changing Literacies. Newark: International Reading Association, 2006. p. 38

ARAÚJO, Peterson M. A. Um estudo de caso em uma escola municipal de João Pessoa, 2006. Disponível em:

http://www.ce.ufpb.br/ppge/Dissertacoes/dissert06/Peterson\%20Martins/LETRAMENTO\%20DIGIT AL.pdf>. Acesso em: 14 set. 2011.

BRASIL. Secretaria de Educação Básica. Orientações Curriculares para o Ensino Médio: linguagens, códigos e suas tecnologias. Brasília: MEC/SEB, 2006. v. 1. p. 85-124.

CARR, P. R.; PORFILIO, B. J. Computers, the media and multicultural education: seeking engagement and political literacy. Intercultural Education, v. 20, n. 2, p. 91-107, 2009.

GEE, James Paul. Good video games and good learning: collected essays on video games, learning and literacy. New York: Peter Lang, 2007.

LUKE, Carmen. Cyber-schooling and technological change: Multiliteracies for new times. In: COPE, Bill; KALANTZIS, Mary (Ed.). Multiliteracies: literacy learning and the design of social futures. London: Routledge, 2000. p. 69-91.

SNYDER, Ilana. The literacy wars: why teaching children to read and write is a battleground in Australia. Sydney: Allen \& Unwin, 2008.

TEIS, Denize T.; TEIS, Mirtes A. A abordagem qualitativa: a leitura no campo de pesquisa, 2006. Disponível em: <http://www.bocc.ubi.pt/pag/teis-denize-abordagem-qualitativa.pdf >. Acesso em: 16 set. 2010.

THE NEW LONDON GROUP. A pedagogy of multiliteracies: designing social futures. In: COPE, Bill; KALANTZIS, Mary (Ed.). Multiliteracies: literacy learning and the design of social futures. London: Routledge, 2000. p. 9-37. 